\title{
Utilisation de pulpe de betterave surpressée par les vaches laitières
}

\author{
F Morel d'Arleux 1, P Le Liboux 2, JM Besancenot 3, JB Galloo 4 \\ IInstitut de l'Elevage, Comité National des Co-produits, 75595 Paris Cedex 12 ; \\ 2Institut de l'Elevage, 75595 Paris Cedex 12 ; 3 Maison de l'Elevage de l'lle de France, \\ 77350 Le Mée sur Seine: ${ }^{4} C E Z, 78120$ Rambouillet, France
}

Dans un essai précédent, nous avons montré l'intérêt d'un apport de pulpes de betteraves surpressées (à raison d'environ $6 \mathrm{~kg} \mathrm{MS} / \mathrm{j}$ ) dans une ration à base d'ensilage de maïs de qualité moyenne, sur la production ef la composition du lait (augmentation du rapport taux protéique/taux butyreux en particulier). L'objectif de cette étude est de confirmer ces résultats avec un ensilage de maïs de bonne qualité.

Deux lots de 15 vaches Holstein, en phase descendante de lactation, ont reçu pendant 105 jours une ration à base d'ensilage de maïs de bonne qualité (34\% de MS) offert à volonté, complémentée par $4,3 \mathrm{~kg} \mathrm{MS} / \mathrm{j}$ d'aliment concentré à base de céréales et de graines de soja extrudé. Cette ration était additionnée (lot P) ou non (lot T) de 6,2 kg $\mathrm{MS} / \mathrm{j}$ de pulpes de betteraves surpressées (à $22 \%$ de MS).
L'apport de pulpe de betterave n'a pas modifié l'ingestion totale. La substitution entre l'ensilage de maïs et la pulpe est presque totale $(0,97)$, ce qui est en accord avec les résultats de Dulphy et al (1978, Bull Tech CRZV Theix, INRA, 34, 15-21).

La production de lait du lot recevant des pulpes a augmenté de $3,0 \mathrm{~kg}$ alors que le taux butyreux a été inférieur de $1,2 \mathrm{~g} / \mathrm{kg}$ et le taux protéique supérieur de $0,8 \mathrm{~g} / \mathrm{kg}$.

Ces résultats sont à relier à la production élevée d'acide acétique dans le rumen due à la digestion des pulpes selon Journet et Chilliard (1985, Bull Tech CRZV Theix, INRA, 30, 13-24).

Cet essai confirme l'intérêt d'utiliser en quantité limitée (6 à $8 \mathrm{~kg}$ de MS par vache et par jour) des pulpes surpressées avec un ensilage de maïs de bonne qualité.

\begin{tabular}{lcc} 
Régime & $\mathrm{T}$ & $\mathrm{P}$ \\
\hline Consommation $(\mathrm{kg}$ de $\mathrm{MS} / \mathrm{VL} \mathrm{j})$ & - & 8,6 \\
Ensilage maïs & 14,6 & 6,2 \\
Pulpe surpressée & - & 0,6 \\
Foin & 0,6 & 4,3 \\
Concentré & 4,3 & 19,7 \\
Total & 19,5 & $26,4^{*}$ \\
Lait $(\mathrm{kg} / \mathrm{j})$ & 23,4 & 42,5 \\
Taux butyreux $(\mathrm{g} / \mathrm{kg})$ & 43,7 & 33,2 \\
Taux protéique $(\mathrm{g} / \mathrm{kg})$ & 32,4 &
\end{tabular}

* : différence entre T et $P$ significative au seuil de $5 \%$ 